of cases by Darwinism where Lamarckism fails. Mimicry and protective colouring, adaptation of flowers to insect visitors, instincts of neuter insects, and Lamarck's chosen case, the giraffe, were among these.

It was then pointed out that breeders have never produced new varieties by transmission of acquired characters (Lamarckian), but always by transmission of congenital characters (Darwinian).

Whilst all this tends to the complete rejection of Lamarck's theory, it is true that Darwin himself admitted Lamarckism as an explanation of some rudimentary organs (disuse), and of some instincts (transmission of acquired habit).

On the other hand, neo-Darwinians reject Lamarckism altogether, because (I) the fundamental fact of transmission of a change of structure or habit acquired during the life of an individual by the action of external agencies is not only not proved but is contrary to experience ; (2) such transmission is highly improbable in view of the structure and origin of the reproductive germs; (3) even if admitted as possible, Lamarckism is not needed in order to explain the facts of the structure and habits of existing plants and animals, in addition to Darwinism.

Pure Darwinism is sufficient.

Finally, the lecturer dealt with some cases advanced by Lamarckians as favourable to their views, and gave their Darwinian explanation.

Among these were rudimentary organs, where the fullydeveloped organ would not be injurious, e.g. the intrinsic muscles of the human ear. These were explained by panmixia and parsimony of growth.

Blind animals in caves and in the deep sea, e.g. blind crayfish, Thaumastocheles, and blind fishes, were shown to be best explained by the natural selection of congenital blindness. Amongst a whole brood of animals swept by a flood into a cavern, or by a current into deep water, those with perfect eyes would escape by following the light, whilst those with con genitally defective eyes would remain and reproduce their defect in their offspring, and in each surcceeding generation the same process of natural selection would be continued.

Wingless insects and birds were similarly explained.

Instincts, e.g. "shamming dead," nest-building, choice of food, were briefly considered, and shown to be explicable by Darwinism and not by Lamarckism.

In fact, it was declared that, in proportion as our knowledge of any class of such facts is extensive and thorough, the Darwinian explanation is found to be correct and the Lamarckian inadequate and inapplicable.

A consideration of the mental evolution of man, according to neo-Darwinism was promised as the subject of a future lecture. It was briefly stated that the results of education and circumstances, good or bad, cannot be transmitted, whilst hereditary qualities, good or bad, cannot be eliminated, except by selection in breeding.

The transmission of acquired experience does not take place by heredity, but (among civilized societies) by the agency of tradition and books.

In civilized societies the injurious effects of unlimited neglect of selective breeding is largely neutralized by panmixia, giving an average race, neither wholly good nor wholly bad.

\section{UNIVERSITY AND EDUCATIONAL INTELLIGENCE}

CAmbridge.-The Botanic Garden Syndicate, unlike some others at Cambridge, have been able to erect their new plant houses within one pound of the estimate, $£ 3000$. The work has been satisfactorily done by Messrs. Boyd, of Paisley. Solid foundations have been laid, so that when required new wood work may be built on the same walls. The new houses include a warm orchid-house, warm fern-house, stove, palm-house, aquarium, and stove-pit. A laboratory, for investigations required to be conducted near the plant-houses, has been built; it contains two large working-rooms and a dark chamber. The collections removed to the new houses are now in capital condition. The hardy cactuses, probably unsurpassed, have been removed to the border in front of the new stove. A new bed has been made for the choicer hardy Ericaceæ. Great progress has been made in naming and labelling. Among plants of scientific interest that have flowered in the gardens is Pilocarpus pennati. folius, which yields pilocarpine, Erythroxylon Coca, Narcissus
Broussoneti (the corona a mere rim), and many others. Among. the most interesting plants received have been Gorbera Jamesoni, a fine Composite from the Cape, Isonandra Gutta (yielding guttapercha), Washingtonia robutsta, a choice new palm, Stachys tuberifera, a new vegetable (the crosnes of the Paris markets), and numerous hardy bamboos.

The regulations altering the arrangement of papers in the Natural Sciences Tripos have been confirmed, making the papers special ones in subjects, instead of general ones covering all the subjects.

The following have been appointed members of the Boards of Electors to Professorships named : Moral Philosophy, Principal Caird ; Chemistry, Prof. A. W. Williamson; Botany, Sir Joseph Hooker; Geology, Prof. A. H. Green; Jacksonian of Natural Philosophy, Prof. A. W. Williamson; Mineralogy, Prof. H. N. Story-Maskelyne; Political Economy, Right Hon. L. H. Courtney ; Zoology, W. H. Flower, C. B. ; Experimental Physics, Sir W. R. Grove; Mechanism and Applied Mechanics, Sir F. J. Bramwell, F.R.S. ; Physiology, Prof. Humphry ; Logic, Prof. Bain.

Mr. A. E. Shipley has been approved as a teacher of Comparative Anatomy for the purpose of medical study.

\section{SCIENTIFIC SERIALS}

The American Journal of Science, February.- Points in the geological history of the Islands Maui and Oahu, Hawaii, by James D. Dana. The subjects illustrated by the present state of these islands are: the conditions of extinct volcanoes in different stages of degradation; the origin of long lines of precipice cutting deeply through the mountains; the extent and condition of one of the largest of craters at the period of extinction, and the relation of cinder and tufa cones to the parent volcano. The accompanying plates, reduced from the recent large Government maps, show the present general features of both islands. Incidental reference is made to the late controversy on Darwin's theory of coral islands, the author declaring emphatically that no facts have hitherto been published by Mr. Murray or Mr. Guppy that prove the theory false, or set aside the arguments in its favour. Some of the facts are more in favour than opposed to it, while none do more than offer a possible alternative.-An experiment bearing upon the question of the direction and velocity of the electric current, by Edward L. Nichols and Wrilliam S. Franklin. The authors, who had already independently developed a method similar to that lately described by Foeppl (Annalen der Physik und Chemie), here repeat his experiment with an apparatus capable of indicating the direction and velocity of the current, supposing it to have direction, even though that velocity were very great indeed. They show that they wowld have been able to detect a change of deflection due to the motion of the coil, even though the velocity of the current had been considerably in excess of one thousand million metres per second.-On the occurrence of monazite as an accessory element in rocks, by Orville A. Derby. The researches of Mr. John Gordon and Prof, Gorceix have placed beyond doubt the wide distribution of monazite in the sea and river sands of Brazil, but under circumstances that give no clue to its origin. The petrographic analyses here described have resulted in the discovery that gneiss, granite, and syenite yield, besides zircon, a certain quantity of microscopic crystals of a heavy yellow mineral apparently identical with the Bahia monazite. Recently, also, Mr. Gordon has obtained residues of zircon and monazite from the river sands at Buenos Ayres, and from gneiss and granite decomposed in situ at Cordoba in the Argentine Republic.-On the use of steam in spectrum analysis, by John Trowbridge and W. C. Sabine. These experiments show that a remarkable degree of economy in time and in waste of apparatus results from the use of a jet of steam in spectrum analysis, when the spark method of obtaining the spectra of metals is employed - A comparison of the electric theory of light and Sir William Thomson's theory of a quasi-labile ether, by J. Willard Gibbs. A comparison is here instituted between the electric theory of light and the new theory of an elastic ether expounded ly Sir William Thomson in the Philosophical Magazine for November 1888 . The result of this inquiry seems to be that both theories in their extreme cases give identical results. The greater or less degree of elegance, or completeness, or perspicuity, with which these laws may be developed by different physicists should weigh nothing in favour of either 
theory. The elastic theory, however, is regarded as somewhat less convenient as a working hypothesis than the electric. - In this number appears Part $\mathbf{I}$ of an exhaustive monograph, with numerous illustrations, on the geology of the volcanic island of Fernando de Noronha, South-West Atlantic, by John C. Branner.

THE Iast volume (xviii.) of the Memoirs of the Kazan Society of Naturalists contains an elaborate inquiry into the distribution of solanin (an alkaloid discovered by Desfosses in many Solanacee) in plants, by $\mathrm{E}$. Wotschall ; short reports on geological exploration in the Governments of Vyatka and Ufa, by A. Netschaef and A. Lavrsky; and a description of the flora of the neighbourhood of Ufa, by A. Gordyaghin.

\section{SOCIETIES AND ACADEMIES. LONDON.}

Royal Society, February 7.- "The Principles of Training Rivers through Tidal Estuaries, as illustrated by Investigations into the Methods of improving the Navigation Channels of the Estuary of the Seine." By Leveson Francis Vernon-Harcourt, M.A., M.Inst.C. E.

After stating the principles upon which the training of the non-tidal portions of rivers are carried out, the undefined and unsatisfactory condition of the principles followed in training rivers through wide tidal estuaries, and the discordant views of engineers on the subject, were pointed out. The absence of definite principles, and the divergence of opinion amongst engineers, have received a remarkable illustration in the great variety of schemes proposed for extending the training walls in the Seine estuary beyond Berville, where the works were stopped, in 1870 , owing to the unexpected changes the work had already produced. It occurred to the author in August r886, that if it should be possible to reproduce, in a working model, the original state of the Seine estuary before the trainin works werc commenced, and next the present state of the Seine, as modified by these works, could be obtained, then the successive introduction in the model of the several schemes, proposed for the extension of the training walls, might furnish results indicating approximately in miniature the changes which the works would actually produce if carried out in the estuary, and also afford a basis for the establishment of general principle for training rivers through wide estuaries. A model, accordingly, was made of the tidal Seine, to the scale of $r / 40,000$ horizontal, and $\mathbf{I} / 400$ vertical ; the bed was formed of fine sand, so that it could be moulded by the current; the fresh-water discharge was produced, at the upper end, by the flow of water from a small cistern; and the tidal ebb and flow were effected by the tipping of a tray, placed at a suitable angle at the lower end, representing the open sea. The model was first worked in November I886, and the experiments were continued at intervals up to 1889 . Silver sand was first used for forming the bed of the miniature estuary; and some of the phenomena of the actual estuary, such as the bore, the "verhaule" or reverse current, and the shifting channels, were reproduced in the model; but when the training walls were introduced into the model, on the lines of the existing training walls, it was found that the silver sand could not be adequately carried in suspension by the small currents in the model to reproduce the accretion which has occurred in the estuary behind and beyond the training walls. A variety of fine powders, of low specific gravity, were consequentiy experimented on in the model, but they mostly proved too sticky, or pasty, or otherwise unsuitable. At last a fme sand from Chobham Common, belonging to the Bagshot beds, containing an admixture of peat, offered better results, and was employed for the subsecuent experiments.

After working the model for some time with a bed formed of this Bagshot sand, the channels assumed a form very closely resembling in general outline the chart of the Seine of I834. This result, by reproducing a former condition of the estuary, confirms the previous results obtained by Prof. Osborne Reynolds with a model of the Upper Mersey estuary, showing that it is quite practicable to reproduce in a model the main tidal channels in an estuary.

The second stage of the investigation involved the quite novel condition of introducing training walls in a model, and producing the resulting accretion. This most essertial stage was the subject of a long series of experiments, but was at last satisfac- torily accomplished with Bagshot sand. The existing training walls were inserted in the model, and the resulting deepening of the trained channel and the accretion outside and beyond were reproduced in the model, and also the shifting channel between the termination of the training walls and the sea.

The third stage of the investigation was then entered upon, consisting in the successive introduction in the model of the lines of the five principal schemes at present advocated, observing the changes they respectively produced in the model of the estuary, and recording then 1 in the form of charts of the estuary, which are appended as plates to the paper. A final experiment was also made with an arrangement of training walls forming as gradually expanding a channel as practicable, without restricting the width of the outlet. The lines designed for the extension of the training walls in each scheme are briefly described in the paper, as well as indicated in the charts, and also the channels and accretion which they each prociuced.

The probability of the results obtained really representing in miniature the results which corresponding works in the estuary of the Seine would actually produce was then considered; for if the effects of any training works could be foreshadowed by experiments in a model, the value of such experiments, in guiding engineers towards the selection of the most suitable design, could not be over-estimated. Though the effects of winds and waves, and the actual rate of accretion, cannot be reproduced in a model, it is evident, from the first stage of the investigation, that the main forces at work, in the comparative shelter of an estuary, are the tidal ebb and flow and the fresh-water discharge, which are the forces which can be produced in a model. Moreover, the correspondence of the second stage of the investigation with the existing state of the Seine estuary confirms the accordance between the results in the model and the condition of the estuary. The extension of training walls decreases the influence of winds and waves ; and therefore the results of the third stage of the investigation are more likely to correspond with the changes which such works would actually produce in the estuary, than those of the first and second stages. Also the results obtained in the model with the two earlier schemes are precisely those which the author predicted would occur, before the experiments were commenced, if the schemes were actually carried out in the estuary.

The paper concludes with a classification of the experiments, with the view of deducing general principles for guidance in training rivers through tidal estuaries. 'The three classes are, (I) outlet of estuary considerably restricted, and channel trained inside towards outlet; (2) channel trained in sinuous line, expanding towards outlet, but kept somewhat narrow at changes of curvature ; (3) channel trained in as direct a course as practicable, and expanding regularly to outlet.

The experiments of the first class exhibited a deep outlet, and a fairly continuous channel inside where the training works were prolonged to the outlet. The channel, however, was irregular in depth near the outlet; and a bar appeared in front of the outlet outside. The breakwater, also, extending across part of the original outlet, occasioned deposits both inside and outside the estuary, by producing slack water in the sheltered recesses.

The second class of trained channel was designed to profit by the well-known scour at the concave face of bends in non-tidal rivers, and to continue the depth thus obtained by restricting the width between the bends. Experiment, however, did not bear out the advantages of this system, probably owing to the variable direction of the flood tide at different heights of tide, its being checked in its progress by the winding course, and not acting in unison with the ebb, from the difference in its direction and the width of the trained channel near the outlet. The third class of trained channel afforded a wide channel, tolerably uniform in depth, in the experiments; the flood tide was less impeded in its progress than with the other forms of training walls, and appeared to act more in concert with the ebb.

The experiments accordingly indicate that the only satisfactory principle for training rivers through wide estuaries with siltbearing currents is to give the trained channel a gradually expanding form, with as direct a course as practicable to the outlet. 'The rate of increase in width between the training walls must be determined by the special conditions of the estuary.

February 14.- "On a Series of Salts of a Base containing Chromium and Urea," No. 2. By. W. J. Sell and Prof. W. J. Lewis.

The paper is a continuation of that published by one of the authors (Proc. Roy. Soc., vol. xxxiii. p. 267). It is here shown 